\title{
On the Lesson Design of Online College English Class during the COVID-19 Pandemic
}

\author{
Zhen Zhou \\ Foreign Language School, Nanchang Normal University, Nanchang, Jiangxi, China
}

\begin{abstract}
The COVID-19 pandemic shocked school education, bringing a lot of challenges. The pandemic has changed how millions around the globe are educated and new solutions for education could bring much needed innovation. During the pandemic, online teaching has become a necessary way for teachers and students in primary schools, middle schools, high schools and even universities around the world. College English teaching becomes increasingly difficult as there are many affecting factors. The article first analyzed the advantages and challenges of the pandemic on the college English online teaching, and then put forward the strategies of online teaching design, in order to supply some reference and enlightenment for the college English teaching in China.
\end{abstract}

Index Terms - lesson design, online college English class, COVID-19 epidemic, educational resources, educational equity

\section{INTRODUCTION}

The novel coronavirus swept China in late January 2020. In order to ensure the life and health of teachers and students at all levels and all kinds of schools, and at the same time to block the spread of virus in large areas among people, the Ministry of Education of China issued the relevant documents on January 29th, 2020 on the postponement of school opening, as well as the use of network platform by students after schools' opening for "non-stop classes". It is a kind of expedient to implement online teaching in the whole country in a special period (Wu, 2019; Luo, 2020; Chen, 2020). Online teaching and offline teaching are very different, which is actually a revolution in the field of education (Li, 2015; Tang, 2019; Wang, 2020). In the face of this new educational reform, teachers should quickly innovate their own educational concepts, learn new means and methods of online teaching, change their teaching methods, tap the resources and potential of online teaching, improve the attractiveness of the course, and enable the students to learn the knowledge through the screen without the on-site supervision of teachers at home ( $\mathrm{Ma}, 2018 ; \mathrm{Li}, 2019 ; \mathrm{Cao}, 2020)$. Besides, how we make good use of the situation to do the ideological and political work of the course in a special period, do a good job in course evaluation, improve the actual effect of course teaching, and strive to do a good job in online courses should arouse the active thinking of educators.

\section{Advantages of OnLine TEACHing}

Online course teaching promotes the reform of teachers' teaching mode and it has many advantages. As a result, education has changed dramatically, with the distinctive rise of e-learning, whereby teaching is undertaken remotely and on digital platforms.

\section{A. Being Safe and Convenient}

During the period of anti epidemic, online teaching is a fairly safe and convenient way of teaching. With schools shut across the world, millions of children have had to adapt to new types of learning. Online classes break the space and time limit, do not need to gather people, so it eliminates the risk of infection and loss. Chinese Educational Department put forward "Non suspension of classes", which refers to the home-based learning mode of online classes, in which all students are unable to attend classes in schools due to this special period. Through the use of online platform teaching, teachers can teach online and students can learn at home online. A teacher can choose to teach at any time that suits $\mathrm{him} / \mathrm{her}$, which means that teachers and students from diverse locations can connect together through online teaching. Online teaching doesn't require any travelling overhead, so a teacher can teach right while sitting at his/her home. Online teaching could thus be perceived as a work from home with flexible schedules. Students have easier access and sharing of information, and it is obvious that any study resource or information in digital format is very easy to be accessed and shared.

\section{B. Optimizing Educational Resources and Promoting Educational Equity}

Optimizing educational resources and promoting educational equity is conducive to individualized teaching. Online courses can address the problem of educational resource inequality, and educational resource sharing enables all students to enjoy the same services. The network class can make use of the computer artificial intelligence convenience, considering students' question and the error rate, can carry on the analysis to each student's study situation, and have the 
pertinence to coach the student. Students can study anytime, anywhere, with strong flexibility, and students can watch playback very conveniently. Taking this year's special situation as an example, the use of online teaching to a large extent ensures "no suspension of classes". We can provide students with the best educational resources and integrate the best teachers in all fields. It is also fair in monitoring students. There is no front row or back row in the class, so the teacher can treat each student equally, and the audio-visual effect is also equal. From the teacher's point of view, there is no need to maintain classroom discipline, which provides more thinking for teachers and how to help students improve the effectiveness and pertinence of learning. Learners will not have too much pressure to study, so they can study easily. This is because of the diversity of internet distance teaching forms with rich artistic experience of audio-visual sense. Instead of the old tradition of "teacher centered, textbook centered, and classroom centered" in the 19th and 20th century, it is student-centered and people-oriented nowadays.

\section{Timely Communication and Feedback}

Timely communication and feedback between teachers and students make teaching more effective. The biggest advantage of online teaching is timely feedback. Through online teaching platform, homework can be collected on the same day, can be corrected, can be fed back to students in time, and usually can receive "thank you" from students. The unfinished list is also clear and teachers do not have to do statistics. This is an incomparable advantage compared with traditional classroom teaching. The traditional teaching method is to assign homework in class and hand it in the next class. It can only be handed out to students before class. The time lag is usually more than 12 hours. The communication between teachers and students is cordial. The biggest charm of online teaching is friendly conversation. With the help of headset and call function, teachers can realize one-to-many teaching, play courseware synchronously, with the help of WPS brush function, demonstrate key points and thinking process, with the help of QQ group classroom, and even play videos. Besides, online teaching also helps in a better administration. One can clearly imagine the administrative challenges to teacher in a traditional classroom than while teaching online. Unlike classroom teaching, a teacher does not have to keep track of multiple students. This decreases the administrative overhead while improving the concentration and performance of a teacher. A majority of online teachers report that online teaching tools have increased their overall efficiency. This is because they are able to organize the course better and are also able to automate certain activities like periodic tests, quizzes, scoring etc.

\section{Wider Student Engagement}

Online teaching incorporates more engagement between students and the teacher. Unlike the interaction in a classroom of numerous students, an online medium provides them with a much closer one-on-one session. Besides, online teaching platform has flexible multifunction and can carry out real-time interaction activities conveniently and can get the feedback and assessment quickly, and also have detailed performance recording, enlarging the students engaging scope and enhancing the teaching equality and teaching efficiency. Besides, the shy and non-participative students, who are not comfortable with participating in classroom discussions, are obviously more likely to participate in an online class. Online teachers often report that students usually perform better and also show more participation in discussions during an online course. According to a recent survey conducted on a group of online instructors, $90 \%$ of the teachers have reported that teaching online helps them to stay more connected with the students and also enable them to have better understanding about every student. Besides, since online education has brought a revolution in the education industry, being a part of it could be a great benefit to every teacher. And from the student's point of view, it has cultivated the students' ability to obtain information analysis information and study in valuable information.

\section{Challenges of Online Teaching}

During the pandemic, online teaching brings a lot of challenges to both teachers and students, and the best way is to accept the challenges and overcome difficulties and find the best teaching and learning way.

\section{A. The Challenge of E-Course Informatization to Teachers}

Because many teachers have no online teaching experience before the epidemic, they are at a loss for online teaching in the face of the sudden outbreak of the epidemic and the issue of the policy of "no school suspension", during the whole epidemic online course, teachers have experienced a great teaching reform, teachers have experienced a lot of progress and growth from being at a loss and anxiety to gradually adapting, slowly getting used to and innovating education and they try to adapt to the change of the new teaching mode and explore the best teaching mode for the course. In the early stage of online class, the main challenge teachers face is the choice of teaching platform. Because there are so many online teaching platforms and apps, teachers do not know how to choose the right online platform for teaching. For example, many teachers choose superstar learning, MOOC, QQ group and Wechat group. As a result, students need to move to different platforms frequently, and there are many programs installed on students' mobile phones or computers. After adapting and exploring, teachers and students finally settle down to one or two teaching platforms. In the middle and later period of online class, teachers are facing the challenge of innovating their own teaching methods, integrating the traditional offline teaching methods with online teaching methods, constantly upgrading and improving their own teaching methods, especially to solve the short board problem of online teaching, 
how to grasp the attention of students and how to improve their participation in the classroom. At the end of online class, teachers need to appease students' anxiety of returning to school, guide students to adjust their mentality, and return to school to actively review for the final exam.

\section{B. The Lack of Self-management Ability of Students}

Although the students have grown up and are college students, most of them still keep the passive learning state in the middle school, and they still need the supervision and guidance of teachers face to face. But the outbreak came out of the blue, and the students did not have any psychological and operational preparation. Therefore, the novel coronavirus pneumonia has a great impact on students' learning behavior, and students' learning habits and behaviors are challenged by them. In the traditional theory class, teachers can grasp students' learning state intuitively, control classroom discipline timely, and master students' learning situation through students' immediate feedback. The online classroom under the epidemic is distance learning, and students can hide behind the screen. In the process of online learning, there may be a phenomenon that teachers are passionate to explain at one end of the network, and students are playing games or even sleeping with teaching videos on the other end of the network. College students themselves are adults, parents will not conduct the same strict management as to primary and secondary school students, which leads to the lack of sufficient supervision and motivation of students' learning state. Students study at home, without textbooks and face-to-face supervision from teachers, which is easy to lead to learning slack. Many students form a bad habit of staying up late during their study at home, browsing web pages and play video games. Their lives are almost empty. Even if asked to sign in twice at a time and interact in class, still many students will stay up late and get up late, appear when they sign in, occasionally appear when they interact, and do other things unrelated to learning at other times. Many students lack of self-control and they have no intention to finish their homework in class. They have been in a state of hesitation and passivity for a long time.

\section{The Challenge to Teachers' and Students'Physical and Mental Health}

During the pandemic, online teaching has a profound influence on both teachers' and students' physical and mental state. On the one hand, long time online teaching each day harms students' eyesight and body development. Many students' eyesight falls to a large extent, and many students' irregular and bad studying and living habits lead to some bad condition or even diseases, such as lack of sleep, inattention, hot-temper, loss of hair, anxiety, depression and insomnia. On the other hand, the sudden change of education mode has reshaped many teachers' teaching way and caused great anxiety. Network teaching seems simple, but actually it is more difficult. Most teachers experienced helplessness, sadness and even anxiety, pain, depression, because the teaching hardware and facilities is insufficient, teaching software is strange, the teaching effect is difficult to guarantee, and teaching forms are not understood and controversial. The challenge to teachers' and students' physical and mental health should be attached great importance to.

\section{College English Class Teaching Design}

During the special pandemic, online teaching is the best choice for teachers and students around the world. Based on the characteristics of college English students, the following will discuss how to design a college English lesson.

\section{A. Infiltrating the Ideological and Political Affect Education and Cultivating the Core Spiritual Quality.}

During the online teaching of epidemic situation, "no suspension of school" enables students to study at home at ease, but students study online for a long time every day, with eyesight fatigue and physical and mental fatigue. Moreover, due to the lack of face-to-face control and guidance from teachers, students are prone to have negative emotions such as learning slackness and weariness. Therefore, the curriculum design urgently needs to incorporate ideological and political affect education into English teaching. Combined with the epidemic situation, students are encouraged to overcome difficulties at home, study hard, be positive, love their country and protect nature. Novel coronavirus pneumonia pictures in China are displayed at the beginning or middle of each classroom teaching. Daily news, video, songs and other ways are employed to discuss between teachers and students and stimulate students' thinking, which can arouse students' emotional resonance, stimulate students' feelings of home and country, cultivate students' patriotism and love for home, unity and benevolence, self-confidence and optimism, protect the core spiritual quality of nature, and cultivate scientific values and world outlook.

\section{B. Introducing Chinese Traditional Culture and Enhancing National Cultural Self-confidence}

As English teaching in universities and primary and secondary schools has always attached too much importance to the teaching of western languages and cultural knowledge, and generally ignored the cultivation of students' ability to express Chinese traditional culture in English, the phenomenon of Chinese cultural aphasia is somewhat serious, many students do not know how to speak Chinese culture in English. At present, the third edition of New Horizon College English has been improved, but it is only reflected in the after-class translation questions, and the content of other parts of Chinese culture is still scarce. Therefore, in the course of teaching design, teachers penetrate the traditional Chinese culture by means of classroom interpretation lead-in, exercises in and out of class translation, video material projection and discussion, so that students can expand and deepen the understanding of the extensive and profound Chinese 
traditional culture, so as to further stimulate students' interest in English learning, improve their English cross-cultural communication ability, enhance national pride, and boost national cultural confidence.

\section{Adopting Simple and Convenient Teaching Platform, and Recorded Class Assisting Online Teaching.}

During online teaching, many students reflect that there are too many teaching platforms, a wide range of apps to be installed, slow mobile internet speed, they are exhausted by online learning and become impatient. In fact, the best platform is suitable for teaching, which is easy to use and convenient. Therefore, teachers can abandon some complex platforms and finally choose the popular software QQ platform (students do not need to install another app) and U-Campus (student information has been entered, login quickly, and teaching material resources are rich), and etc. The teaching is mainly carried out through online voice message, text message, voice phone, screen sharing and other ways on QQ platform, fully tapping the potential powerful functions of QQ homework, continuing, voting, photo album, etc., and love course MOOC and video broadcasting course play an auxiliary role. Because MOOC class only involves some units of reading and writing textbooks, the second and fourth units of reading and writing textbooks and the key contents of audio-visual and oral textbooks need to be explained in the form of recorded broadcast class. In class discussion, free talk, translation questions in and out of class, and reading comprehension questions of 10 choices out of 15 words will also be explained and taught in the form of recorded broadcast class. Because the teacher wants the best effect of the recorded and broadcast class, the preparation time is longer, more complicated and more laborious than the online live broadcast preparation, but its advantages are: clear explanation, time-saving and efficient, flexible use, and the students more approved of this teaching method.

\section{Continuously Improving Teaching Methods based on the OBE Teaching Concept}

OBE teaching concept advocates student-centered, outcome oriented, reverse design teaching and continuous improvement of teaching. Under the guidance of the OBE teaching concept, the teaching design should fully consider the learning situation, combine the online explanation with the MOOC class and the video broadcast class, and organically integrate the CET-4 training into the textbook teaching (the QQ voting survey shows that the students reach a consensus -- the biggest goal of this semester is to pass the CET-4 smoothly), and launch the China Daily News discussion, video discussion and free in the class talk training and extracurricular practice should be extended appropriately, and students' comprehensive English literacy should be improved. However, it is difficult for online teaching to pay attention to students' dynamics, so discussion and submission of photo taking homework will be set up in class to pay attention to students' learning status in real time. Teachers learn about the students' feedback on teaching through the QQ platform, QQ voting and communication with students. For example, a few students think that there are too many extracurricular assignments. In view of this situation, the teacher reflected on teaching, realizing the difficulty of students' online learning, making corresponding adjustments, moderately reducing the amount of homework, and dividing the homework into required and optional. The adjustment of homework takes into account the individual differences of students, so that students can learn Students have more independent learning space. After class teachers also suggest that teachers and students read more together, share English learning resources and learning methods in QQ group, and grow together.

\section{E. Paying Attention to Students' Learning Enthusiasm and Being Good Teachers and Friends to Students.}

During the online teaching of epidemic situation, generally speaking, it is very difficult for students to attend classes. Teachers need to understand students' learning and ideological trends in real time, and then make positive feedback and guidance. During online teaching, it is understood that students encounter various difficulties, such as: (1) online learning equipment problems: some students only use mobile phones for class and have no computers available; some students have very slow internet speed and even have no signals from time to time, and some students sometimes cannot attend classes because their families need mobile phones for class. (2) There are difficulties in online teaching participation: some students live in relatives' houses during the epidemic due to their parents' work outside, and they need to help with their relative's cooking, and they are not willing to participate in the classroom (relatives' parents ignore online teaching); some students' parents need to be accompanied and taken care of when they are ill, so it is very difficult to participate in learning; many students study at home due to the epidemic, stay up late, work and rest irregularly, and lack of devotion in class; and some students are addicted to playing games at home, and conduct passive learning in class. (3) Lack of self-control, impetuous mood, worrying about English learning and CET-4, but not wanting to make efforts. There is a great sense of learning slack and helplessness. The situations of students are different. According to different situations, teachers need to pay close attention to them, give proper guidance, encouragement and help in a timely and appropriate manner; pay more attention to the progress of students, and praise and feedback in time.

\section{F. Cultivating Students' Innovative Thinking with Interactive and Positive Classroom Discussion}

In the past two months, the online teaching situation shows that: compared with the traditional face-to-face classroom, students in the online teaching classroom are more confident and active, participate more actively, speak more actively and express their views more freely. This situation deserves our teachers' attention. Teachers should integrate the rich experience accumulated in the recent online teaching into the face-to-face classroom teaching in the future. They should 
combine the traditional offline teaching and online teaching organically, explore an efficient mixed teaching mode, communicate with students through multiple channels and ways, carry out teaching, teach students according to their aptitude, and improve teaching efficiency. In the teaching of this course, QQ voice phone, QQ chat group and QQ homework (can send voice homework, timely feedback) provide a very good and convenient interactive platform for teachers and students. In general, classroom discussion is centered on the current epidemic news, current affairs and politics, students' life and textbook teaching content. Students are widely involved and actively thinking. Their innovative thinking ability and comprehensive English language ability are generally improved. According to the students' discussion results, teachers will make written comments or voice comments or video comments, give timely feedback, and promote teaching.

\section{CONCLUSION}

In short, during the house closure period of COVID-19 epidemic, online teaching is a best choice, which is also a matter of expediency in the special period. Online teaching has advantages and challenges, and we should make a good use of them and design our college English class well. Teachers can design considering such aspects as infiltrating the ideological and political emotion education and cultivating the core spiritual quality, introducing Chinese traditional culture and enhancing national cultural self-confidence, adopting simple and convenient teaching platform, and recorded class assisting online teaching, continuously improving teaching methods based on the OBE teaching concept, paying attention to students' learning enthusiasm and being good teachers and friends to students, and cultivating students' innovative thinking with interactive and positive classroom discussion. Teachers and students can benefit from the online teaching, learn and grow together, contributing a lot to our country's anti epidemic battle.

\section{ACKNOWLEDGMENTS}

This study was financially supported by the Project of Humanities and Social Sciences of Jiangxi Province Higher Education: "Application of Whole Person Education Theory in Foreign Language Education of Normal Universities" (JC161005), the Project of The 13th Five-Year Plan of Educational Science in Jiangxi Province "An Empirical Study on the Impact of Internship on the Development of English Teachers' Teaching Ability" (17YB266) \& "11531" Construction Project of Nanchang Normal University of China (English Language and Literature Discipline Construction).

\section{REFERENCES}

[1] Cao Chongli. (2020). The practical research on the continuous learning ability of the students after the suspension of classes. Progress: Teaching and Research, 4:10-11.

[2] Chen Hong, Wu Wenqing. (2020). Positive language helps win the battle of perseverance: four steps for students' psychological growth: homestead, online class, resumption of study and classroom. Basic Education reference, 4: 3-7.

[3] Li Mei, Wang Shuangshuang. (2019). Analysis of problems in online teaching activities of open university courses. Journal of Jilin radio and Television University, 1: 3-4.

[4] Li Peiqian, Chi Xiaoting, Zhao Haixia. (2015). Research on the reform of university teaching mode under the background of online course: Based on the empirical research of a university in Changchun area. New Course Research: the Middle of the Year, 6: $31-32$

[5] Luo Yan. (2020). The dilemma of rural online courses to be solved. Minsheng Weekly, 5: 56-57.

[6] Ma Ning, Hu Jiaxu. (2018). Online teaching inspection: Problems and reflections. Journal of Jilin radio and Television University, 1: 23-24.

[7] Tang Si. (2019). Analysis of online teaching live broadcast and recording broadcast. Digital Design, 17: 86-88.

[8] Wang Aisheng. (2020). Eliminating anxiety and making online courses efficient and orderly. China Information Technology Education, 5: 11-13.

[9] Wu Liqing. (2019). Investigation and Research on the current situation of French online courses in the context of Internet. Research on Communication Power, 31: 213-215.

Zhen Zhou was born in Ezhou, Hubei province, China in 1981. She received her master degree in English teaching method from Hubei University, China in 2008.

She is currently an associate professor in the School of Foreign Languages, Nanchang Normal University, Nanchang, China. Her research interests include English teaching psychology and English teaching method. 